\title{
High Grade Broad Ligament Serous Adenocarcinoma
}

National Cancer Institute

\section{Source}

National Cancer Institute. High Grade Broad Ligament Serous Adenocarcinoma. NCI

Thesaurus. Code C126481.

A rapidly growing serous adenocarcinoma that arises from the broad ligament. It is characterized by the presence of high grade cytologic features and frequent mitotic figures. 